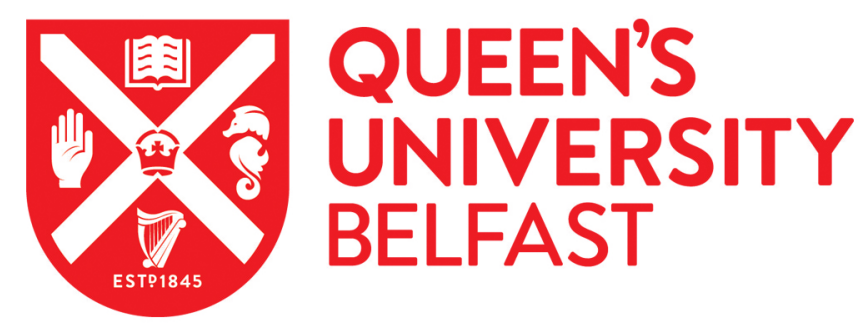

\title{
A Methodology to Forecast the Control Capacity and Control Payback of a Population of Thermostatically Controlled Appliances in a
} Demand-Side Management

Yazdkhasti, P., Diduch, C. P., \& Elkhateb, A. (2021). A Methodology to Forecast the Control Capacity and Control Payback of a Population of Thermostatically Controlled Appliances in a Demand-Side Management. Canadian Journal of Electrical and Computer Engineering , 44(2), 136 - 142.

Published in:

Canadian Journal of Electrical and Computer Engineering

Document Version:

Peer reviewed version

Queen's University Belfast - Research Portal:

Link to publication record in Queen's University Belfast Research Portal

Publisher rights

Copyright 2020 IEEE. This work is made available online in accordance with the publisher's policies. Please refer to any applicable terms of use of the publisher.

\section{General rights}

Copyright for the publications made accessible via the Queen's University Belfast Research Portal is retained by the author(s) and / or other copyright owners and it is a condition of accessing these publications that users recognise and abide by the legal requirements associated with these rights.

Take down policy

The Research Portal is Queen's institutional repository that provides access to Queen's research output. Every effort has been made to ensure that content in the Research Portal does not infringe any person's rights, or applicable UK laws. If you discover content in the Research Portal that you believe breaches copyright or violates any law, please contact openaccess@qub.ac.uk. 


\section{A Methodology to Forecast the Control Capacity and Control Payback of a Population of Thermostatically Controlled Appliances in a Demand-Side Management}

\author{
Pegah Yazdkhasti \\ Electrical \& Computer Engineering \\ University of New Brunswick \\ NB, Canada \\ Email: \{pegah.ykh@unb.ca\}
}

\author{
C.P. Diduch \\ Electrical \& Computer Engineering \\ University of New Brunswick \\ NB, Canada \\ Email: \{diduch@unb.ca\}
}

\author{
Ahmad Elkhateb \\ School of Electronics, Electrical Engineering \\ and Computer Science \\ Queen's University Belfast \\ Belfast, United Kingdom \\ Email: \{a.elkhateb@qub.ac.uk\}
}

\begin{abstract}
Integrating renewable resources such as wind and solar into the existing power system has introduced new challenges due to their rapid fluctuations which tends to decrease the reliability of the grid. One method to cope with this uncertainty and variability in generation is managing the demand side through direct load control. Thermostatically controlled appliances can play a significant role for this purpose; however, the system operator requires a reliable estimation about the magnitude of the load and how much it can be shifted. This paper presents a novel methodology to formulate and forecast the control capacity of a population of thermostatically controlled appliances. In addition to that, this methodology can provide an estimation on how long the system can follow a desired level of power consumption, and how the aggregated load would change once the controller stops (ie. the payback). The performance of the proposed method was evaluated using a numerical simulator of a population of the loads. Simulation results show that the proposed method can provide a reliable estimation about controllability of the load in terms of minimum and maximum achievable load, the time interval that it can hold the load at certain level, and how the uncontrolled load would behave after the control period.
\end{abstract}

Index Terms-Thermostatically Controlled Appliances, Smart Grid, Demand-Side Management, Direct Load Control, Control Capacity, Control Payback

\section{INTRODUCTION}

Use of clean energy such as wind and solar are increasing rapidly during the past decade [1]. However, penetration of renewable resources have introduced new challenges such as fast fluctuation of the generation to the gird. This may reduce the reliability and quality of the electric power systems [2]. Although through the use of energy storage devices such as batteries, the fast fluctuations of the wind and solar may be smoothed [3], the energy storage will increase the cost of renewable deployment.

Direct Load Control (DLC) is a cost-effective method in managing the demand side (DSM) to cope with the intermittency of the generation [4]. Numerous recent studies have shown that the aggregated power consumption of thermostatically controlled load (TCL), such as electric water heaters or air conditioners, may be effectively controlled through adjusting their set points or operation time to reshape the aggregated power consumption [5]-[10].

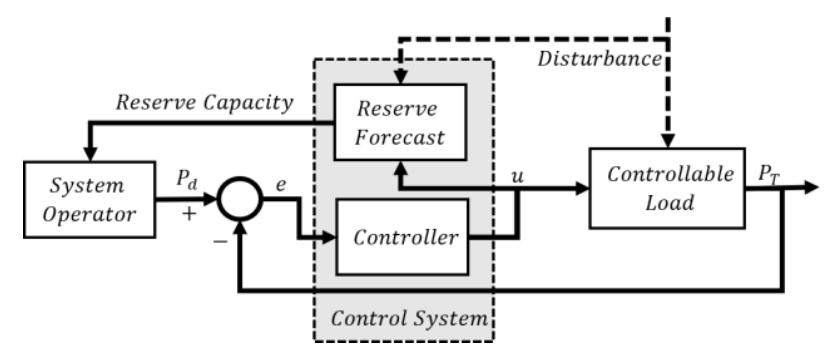

Fig. 1: A block diagram for direct load control system

To efficiently control the demand-side to match with renewable generation, an accurate forecast of the power consumption profile is required to allow the system operator to dispatch feasible instruction. Figure 1 illustrates a general structure of such a system, where the control system will provide a forecast profile of the demand and the capacity to reshape it to the system operator. Then, based on this information combined with the forecast of the renewable generation, the system operator can decide how much the controller should increase or decrease the load to balance the load with generation. This research will focus on developing a methodology to provide a fast and accurate forecast on controllability of the load.

There are various studies on developing a mathematical models for the aggregate demand of the air conditioners in recent years. One commonly studied problem is designing a control strategy to adjust the thermostat set point in order to reduce the peak of the demand and mitigate the effects of variability of the renewable energy [11]-[15]. Other approaches consider the direct control of ACs compressors states in centralized control strategies [12], [16], and distributed and decentralized control strategies [17]-[19].

Many different methods have been proposed to forecast the controllable load. A neural network forecasting method is presented in [20]-[22] to forecast the air conditioning power consumption of a hospital based on temperature, humidity and historical power consumption. A regression-based algorithm combined with Kalman filter is presented in [23] to forecast the air-conditioning load using historical data. Gao et. al [24], proposed a least square support vector machine to create a 
short-term load forecast.

Although these methods provide a good estimation on load forecast, they may not be practical when historical power consumption are not available either for training the algorithm or using for pattern recognition. Another problem is that none of these methods provide information about how much the load can be changed due to a control action, or how it will behave once the controller stops.

The main contribution of this paper is to introduce a modelbased forecasting method that provides a short-term forecast of the uncontrolled load (ie. baseline) combined with an estimation on maximum and minimum achievable level of power consumption when controlling the load. A Mathematical model is also developed to estimate how long a controller may be able to follow a desired load (given by the system operator) without disturbing the customers. Also, this model can predict how the aggregated power consumption will change after the control period.

The rest of this paper is organized as follows: A brief description of the individual and aggregated load modeling is presented in Section II. The definition of the control capacity and methodology to estimate it are described in Section III. Section IV presents the methodology to predict the behavior of the load when the system operator dispatches a desired load and when it releases the control. The Simulation results are discussed in Section V, and Section VI concludes the paper.

\section{Modeling THE LOAD}

\section{A. Individual Load}

Let $m(t)$ denote the on/off state of the air conditioner at time $t$, and $T$ denote the room temperature, then the changes in the room temperature are governed by equation (1), which is widely used in literature [16], [25]-[31]:

$$
\begin{gathered}
T(t)=-\frac{1}{C R}(T(t)-T a(t)+m(t) R P \text { nom }) \\
\square 0, \quad \text { if } T(t) \leq T_{s}-\Delta T \\
m\left(t^{+}\right)=\begin{array}{l}
1, \quad \text { if } T(t) \geq T_{s}+\Delta T \\
\square(t), \text { otherwise }
\end{array}
\end{gathered}
$$

where $R$ denotes the thermal resistance of the room, $C$ denotes the thermal capacitance of the room, $T_{a}$ is the ambient temperature, and $P_{\text {nom }}$ is the nominal power rating of the air conditioner. Once the room temperature rises to the higher threshold setpoint, the air conditioner will turn on $\left(T_{s}+\Delta T\right)$ to decrease the room temperature until it reaches the lower threshold $\left(T_{s}-\Delta T\right)$.

By replicating the individual air conditioners with various thermal characteristics and initial conditions, an aggregated system can be created.

Considering a population of $N$ ACs, let us assume that the nominal power rating $\left(P_{n o m}\right)$, thermal resistance $R$, ambient temperature $\left(T_{a}\right)$ and the thermostat set points are the same for all ACs. Since the changes in ambient temperature are typically much slower than the natural dynamics of the aggregated demand response, it can be justified to use a linear parameter-

\begin{tabular}{|c|c|c|}
\hline Parameter & Value & Description \\
\hline$P_{\text {nom }}$ & $2 k W$ & $\begin{array}{l}\text { Nominal power rating of the air condi- } \\
\text { tioner }\end{array}$ \\
\hline$R$ & $2^{\circ} \mathrm{C} / \mathrm{kW}$ & Thermal resistance \\
\hline$\mu_{C}$ & $3.6 \mathrm{kWh} /{ }^{\circ} \mathrm{C}$ & Mean value of the thermal capacitance \\
\hline$\sigma_{\text {rel }}$ & 0.2 & $\begin{array}{l}\text { Standard deviation of log-normal distri- } \\
\text { bution for thermal capacitance }\end{array}$ \\
\hline
\end{tabular}
varying (LPV) model structure, where the AC population is
TABLE I: Simulation Parameters

heterogeneous solely in thermal capacitance $C$, which is lognormally distributed with mean $\mu_{C}$ and standard deviation $\sigma_{C}=\sigma_{r e} \mu_{C}$. [17], [28]. Then, the total power consumption of the ACs, $P_{T}(t)$ will be a function of the two input variables: thermostat set point, and ambient temperature.

The total aggregated power consumption and the normalized aggregated power of a group of $N$ ACs, denoted by $P_{t}(t)$ and $P(t)$ respectively, are given by:

$$
\begin{gathered}
P_{T}(t)=m_{i=1}(t) P_{n o m} \\
P(t)=\frac{\sum_{\substack{N=1 \\
\sum}} m_{i}(t) P_{n o m}}{\sum_{i=1}^{N} P_{n o m}}=\frac{\sum_{i=1}^{N} m_{i}(t) P_{n o m}}{N P_{n o m}}
\end{gathered}
$$

Equation (4) provides a convenient way to numerically study aggregate demand dynamics. By simulating an artificial array of $N$ independent sets of equations (1) coupled with equation (4), we can analyze the effect of input variables (thermostat set point and ambient temperature) on the aggregate power demand of the population.

The authors have shown in [32] that the aggregated power consumption can be formulated as:

$$
P(t)=P_{s s}\left(T_{a 0}, T_{s 0}\right)+\mathrm{L}^{-1}\left\{U_{a}(s) H_{a}(s)-U_{s}(s) H_{s}(s)\right\}
$$

where $P_{s s}\left(T_{a 0}, T_{s 0},\right)$ is the initial steady state power consumption, $\mathrm{L}^{-1}$ is the inverse Laplace transform, $U_{a}(s)$ and $U_{s}(s)$ are the Laplace transform of the changes in the ambient temperature and thermostat setpoint respectively: $U_{a}(s)=$ $\mathrm{L}\left\{T_{a}(t)-T_{a 0}\right\}$ and $U_{s}(s)=\mathrm{L}\left\{T_{s}(t)-T_{a 0}\right\}$

$H_{a}$ and $H_{s}$ are the system transfer functions respect to the ambient temperature and thermostat setpoint respectively:

$$
H_{a}(s)=\frac{a_{2} s^{2}+a_{1} s+a_{0}}{s^{2}+2 \xi_{1} \omega_{n 1} s+\omega_{n 1}^{2}}
$$

where $a_{2}=0.016, a_{1}=0.0005, a_{0}=0.0002, \omega_{n 1}=0.05$ and $\xi_{1}=0.12$., and:

$$
H_{s}(s)=\frac{c_{2} s^{2}+c_{1} s+c_{0}}{s^{2}+2 \xi \omega_{n 2} s+\omega_{n 2}^{2}}
$$

where $c_{2}=0.51, c_{1}=0.06, c_{0}=0.0002, \omega_{n 2}=0.04$ and $\xi_{2}=0.09$. It should be noted that these values are obtained using the MATLAB System Identification Toolbox. More details about this system identification is presented in [32].

Figure 2 illustrates an example of using the combined model when both inputs are changing and compares the results with the simulation of 10, 000 ACs with the parameters listed in Table I. In this example, the ambient temperature rises from $26^{\circ} \mathrm{C}$ to $28^{\circ} \mathrm{C}$ at minute 500 . Then, the thermostat set points 

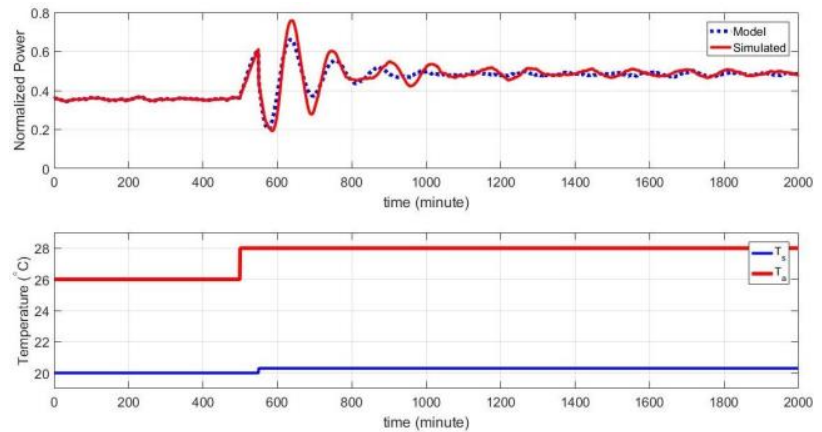

Fig. 2: Comparing the Model's output and aggregated simulation's output to the change in the ambient temperature and thermostat set points [32]

are increased from $20^{\circ} \mathrm{C}$ to $20.3^{\circ} \mathrm{C}$ at minute 550 . figure 2 compares the simulation results of 10,000 ACs for this input patterns with the output obtained from the mathematical model represented by Equations (6) and (7).

\section{CONTRol CAPACITY}

The controller may change the $T_{s}$ to adjust the aggregated power consumption to follow a desired load. One method to consider customers' comfort is to impose limit on the range of changing $T_{s}$. Let us assume that the initial preferred thermostat setpoint of a group of the load is denoted by $T_{s 0}$, then the controller may only change the $T_{s}$ in the range of $\left[T_{s 0} \alpha, T_{s 0}+\alpha\right]$ where $\alpha$ characterizes the comfort zone. Once the $T_{s}$ reaches these limit, the controller is not allowed to go beyond this range, and thus, it cannot control the aggregated power any more. This is the time when there is no more reserve capacity.

In this section, a definition for the reserve capacity is presented and a methodology is proposed to forecast how much reserve capacity is available at each point in time.

\section{1) Definition}

Reserve capacity is defined as the power profile and its energy over a time window that can be added to or removed from the baseline load (i.e. when there is no external control), without disturbing the customers (i.e. the $T_{s}$ remains within a certain range).

This definition can help us predict how much the baseline load can be increased or decreased; and how long the controller can follow a desired aggregated power (energy = power $\times$ time). With this definition of reserve capacity, the system operator can determine if a set point is attainable and for how long it can be maintained.

\section{2) Methodology}

Let us assume that the controller may change the thermostat setpoint of the TCAs within $\left[T_{s} \min , T_{s} \max \right]$. Also, let us assume that at time $t_{0}$, the thermostat setpoint of the TCAs are $T_{\mathrm{s} 0}$ and a forecast of the $T_{a}$ is available for the next $\Delta t$ time window.

Using the aggregated system model presented in Section II, it is possible to obtain an estimate on the aggregated power using $T_{a}$ and $T_{s}$. Using the forecasted $T_{a}$, the baseline can be obtained when there is no change in $T_{s}$, the upper boundary of the power profile $\left(P_{\max }\right)$ can be obtained when $T_{s}=T_{s}^{\min }$,
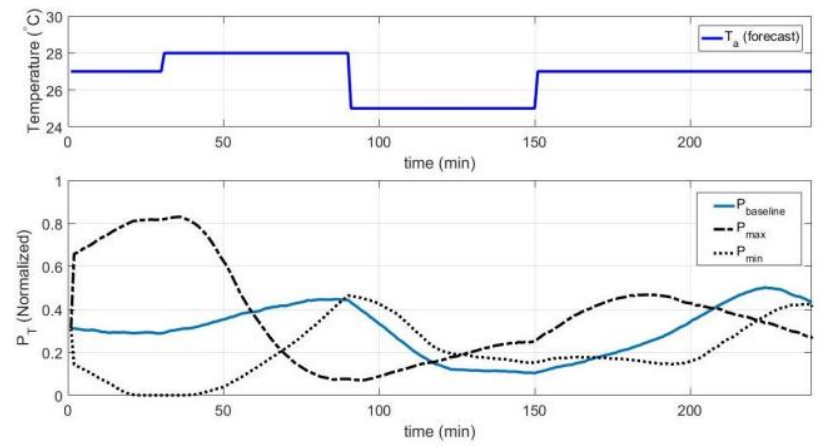

Fig. 3: At time 0, with a forecast of $T_{a}$, the profiles for $P_{\max }, P_{\text {baseline }}$ and $P_{\min }$ can be calculated from the system model

and the lower boundary $\left(P_{\min }\right)$ can be obtained when $T_{\mathrm{s}}=$ $T_{s}^{\max }$, as shown in Figure 3.

$$
P_{\text {baseline }}=P_{s s}\left(T_{a 0}, T_{s 0}\right)+\mathrm{L}^{-1}\left\{U_{a}(s) H_{T}(\S)\right\}
$$

$$
\begin{gathered}
P_{\max }=P_{s s}\left(T_{a 0}, T_{s 0}\right)+\mathrm{L}^{-1}\left\{U_{a}(s) H_{a}(s)-\right. \\
\left.U_{s} \max (s) H_{T_{s}}(s)\right\} \\
\Rightarrow P_{\max }=P \quad \text { baseline }+\mathrm{L}^{-1}\left\{\frac{T_{s 0}-T_{s}^{\min }}{s} H_{s}(s)\right\}
\end{gathered}
$$

and

$$
\begin{aligned}
& P_{\min }=P_{s s}\left(T_{a 0}, T_{s 0}\right)+\mathrm{L}^{-1}\left\{U_{a}(s) H_{a}(s)-\right.
\end{aligned}
$$

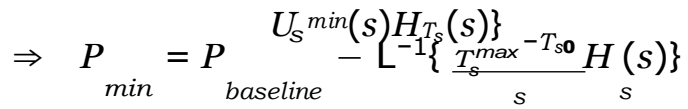

Figure 3 depicts an example for these calculations. The top curve in this figure is a forecast of the ambient temperature.

Feeding this curve to Equation (8) will create the baseline forecasted load shown by the blue curve on bottom graph.

Applying $T$ max and $T$ max in Equations (9) and (10) will generate a forecasted maximum and minimum power, shown in dashed and dotted curves in the bottom graph in this figure.

The $P_{\min }$ and $P_{\max }$ illustrates the boundaries that a system operator may dispatch, and the controller can follow it while maintaining customers' comfort.

\section{Control Payback}

The system operator requires a variety of information to decide how to reshape the aggregated demand. From the load controller, In addition to the information about the capabilities to increase or decrease the load, it is also useful to know that how long a controller can stay at a desired level without disturbing the customers (as described in Section III), and how the load will behave, if the dispatch command is over.

\section{A. Hold Time}

The time interval that a controller could alter the load at a certain point depends on the available energy to be shifted. Using the forecasted load profiles obtained by the system model, the amount of energy that can be added to/removed 
from the baseline energy (reserve capacities) during this $\Delta t$ time window can be calculated as:

$$
\begin{aligned}
& \int_{t_{\mathbf{0}}+\Delta t} \\
& E_{\text {added }}=t_{t_{0}}\left(P_{\max }(t)-P_{\text {baseline }}(t)\right) d t \\
& \boldsymbol{J}_{t_{\mathbf{0}}}+\Delta t \\
& E_{\text {removed }}=t_{t_{0}}\left(P_{\text {baseline }}(t)-P_{\min }(t)\right) d t
\end{aligned}
$$

If the system operator issues a $P_{\underline{x}} P_{\text {baseline, }}$ then the controller can follow this desired level until tend when the amount of added energy is equal to the reserve capacity:

$$
E_{\text {added }}-\int_{t_{0}}^{t_{\text {end }}}\left(P_{d}(t)-P_{\text {baseline }}(t)\right) d t=0
$$

Thus, tend is them time when:

$$
\int_{t_{\text {end }}}\left(P_{\max }(t)-P_{d}(t)\right) d t=0
$$

And similarly, if the $P_{d} \leq P_{\text {baseline }}$, then the system can follow this desired level until $t_{\text {end }}$ when:

$$
\int_{t_{\text {end }}}\left(P_{d}(t)-P_{\min }(t)\right) d t=0
$$

Therefore, the system operator can easily calculate how much energy is available (by using the forecasted $P_{\min }$ and $P_{\max }$ ), and then dividing it by $P_{d}$ will give an estimation that how long the controller can stay at this power level.

\section{B. Payback}

It is important to know how the load may behave when the

dispatch interval of the system operator is finished, in order to prevent unwanted new peaks or fast oscillations.

Due to the assumption of linear systems, it can be deduced that if $T_{\mathrm{s} 0}-T_{s} \min$ is required to go from $P_{\text {baseline }}$ to $P_{\max }$, then the amount of changes in thermostat setpoint in order to increase the load to $P_{d}$ would be:

$$
\Delta T_{s 1}=\frac{P_{d}-P_{\text {baseline }}}{P_{\text {max }}-P_{\text {baseline }}} \times\left(T_{s 0}-T_{s 1}^{\min }\right)
$$

Therefore, it can be assumed that at the end of control interval, the thermostat set point will converge to this value. Hence, the uncontrolled load after this time may follow the normal step response to the thermostat setpoint change, which can be calculated using Equation 5:

$$
P(t)=P_{s s 0}+\mathrm{L}^{-1}\left\{U(s) H(s)-\frac{\Delta T_{s}}{s} H_{s}(s)\right\}
$$

where $P_{s s 0}$ is the aggregated power at the beginning of the forecast interval.

Similarly, when the $P_{d}$ is less than the $P_{\text {baseline, }}$

$$
\Delta T_{s 2}=\frac{P_{\text {baseline }}-P_{d}}{P_{\text {baseline }}-P_{\text {min }}} \times\left(T_{s 0}-T_{s}^{\text {max }}\right)
$$

and the power may look like:

$$
P(t)=P_{s s 0}+\mathrm{L}^{-1}\left\{U_{a}(s) H_{a}(s)+\frac{\Delta T_{s 2}}{s} H_{s}(s)\right\}
$$

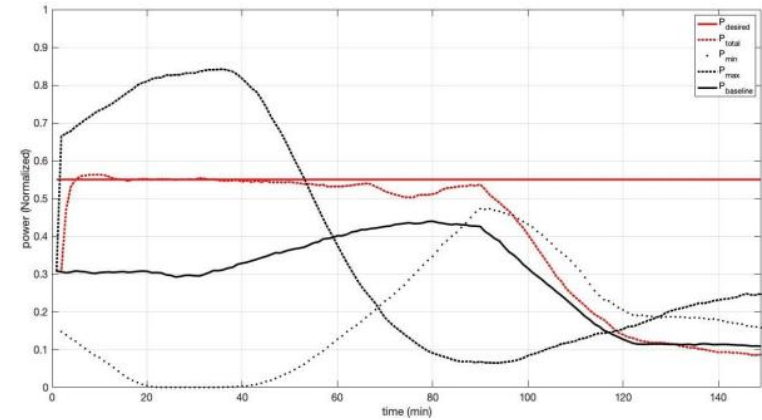

Fig. 4: Forecasted control capacity and simulated load following for an arbitrary dispatch instruction $\left(P_{d}=0.55\right)$

\section{Performance Analysis}

To evaluate the reserve capacity, various scenarios have been designed with various profiles of the $T_{a}$ and $P_{d}$. As an example shown in Figure 4, it is assumed that the initial $T_{s} 0=22^{\circ} \mathrm{C}$ and the customer comfort constraints are: $T_{s}^{\mathrm{min}}=21.5^{\circ}$ and $T_{s} \max =22.5^{\circ} \mathrm{C}$. The ambient temperature has a forecasted profile as depicted in Figure 3.

\section{A. Reserve Capacity}

Using the aggregated model of the load, based on the forecasted $T_{a}$, the system will create a forecasted load for $P_{\min }$ and $P_{\max }$ and baseline, when $T_{s}$ is set to $T_{s}^{\max }, T_{s}^{\min }$ and $T_{\text {so }}$ respectively, as shown in Figure 4 . These curves show the attainable $P_{d}$, and also to determine how long the controller can maintain a certain desired output (e.g $P_{d}=0.55$ ), it simply find $t_{\text {end }} \int_{t_{\text {end }}}\left(P^{\max }(t)-P_{d}(t)\right) d t=0$, as shown in Figure 5. In this example, it is predicted that the system has enough energy to hold the desired output at $P_{d}$ for about 85 minutes.

The goal of this paper is to evaluate the proposed methodology for estimating the reserve capacity, and not the design of an optimized controller. Hence, a simple PI controller $\left(H_{c}(s)=\frac{0.9}{s}\right)$ was implemented in MATLAB [33] to control the changes of $T_{s}$ of the ACs in order to follow the given $P_{d}$.

Some coding constraints were also added to this controller to prevent it from changing the thermostat set points beyond the $\left[T_{\mathrm{s} 0}-\alpha, T_{\mathrm{s} 0}+\alpha\right]$. Simulation results for this controller is also depicted in Figure 4 (The dotted red curve). As can be seen in this figure, this controller can actually follow this desired load for about 80 minutes, before hitting the thermostat constraints, and therefore, cannot reduce the set points any further to maintain customers' comfort. This results in ACs to begin turning off, which is the reason that the aggregated power consumption starts dropping at this point.

The energy curve depicted in Figure 5 is obtained from Equation 14 which assumes an ideal controller that holds the aggregated power $P(t)$ exactly at the desired value $P_{d}$. However, due to control errors (during settling time, overshoots,...), the exact energy consumption is different from the ideal energy consumption of Equation 14, which is resulting in approximately 5 minutes error in estimating the $t$ end. 


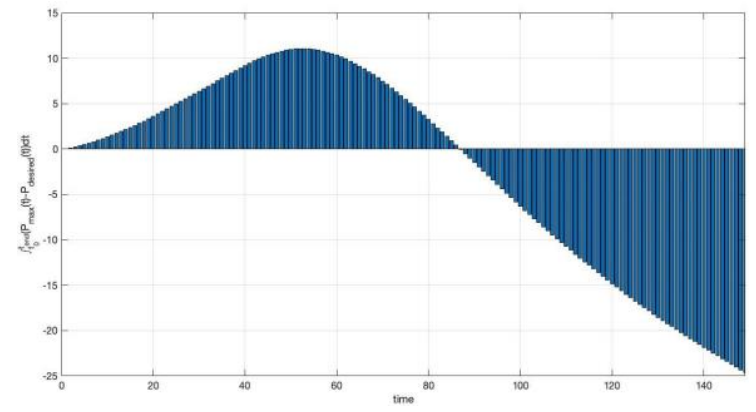

Fig. 5: Predicting how long the controller can follow an arbitrary dispatch instruction $\left(P_{d}=0.55\right)$ using Equation (14)

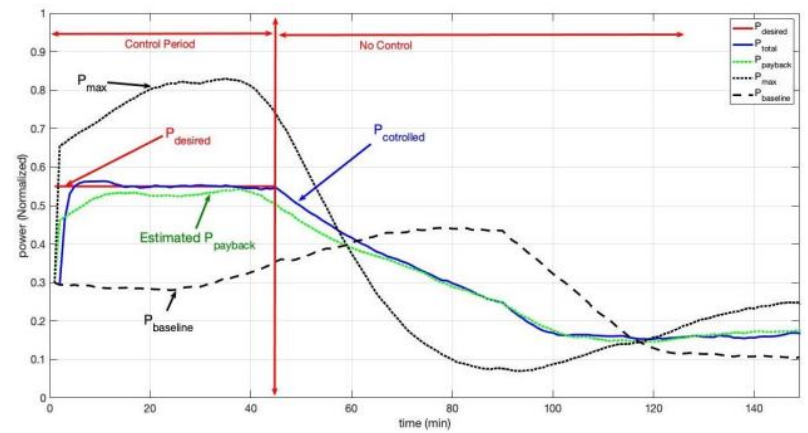

Fig. 6: Predicting how the load will behave once the controller stops after 45 minutes of controlling the load

\section{B. Control Payback}

Considering the scenario discussed in Section V-A, the system in the given condition can follow a dispatch command $P_{d}=0.55$ for about $t_{\text {end }}=80$ minutes (by solving Equation (14)). However, due to other conditions, let us assume that the system operator decides to issue this command for 45 - minutes, as shown in Figure 6.

In order to forecast the behavior of the load after this dispatch interval, we can use Equation (16) and (17). The solution for $P(t)$, in this scenario, is the green dotted in Figure 6 . The simulation results to follow the given desired set point has produced the blue curve in this figure. This results show that the Mathematical model can provide a good estimation on how the load may behave after the control interval to model the payback effect of the control actions.

Another scenario was also studied where $P_{d}=0.15$, and the command was dispatched for a 45 minutes interval, as depicted in Figure 7. Using the method presented in Section IV, the expected load profile after the dispatch interval can be obtained using Equation (16) and (17 where the solution to this equations is shown as the dotted green curve in Figure 7. The simulation results for the controller to follow this dispatch instruction is also depicted as the blue curve in this figure. Despite the large error right after the control interval, it can be observed that the new peak and the converged final values are very close to each other, and thus, this model can still provide a useful and reliable information about the payback of the system.

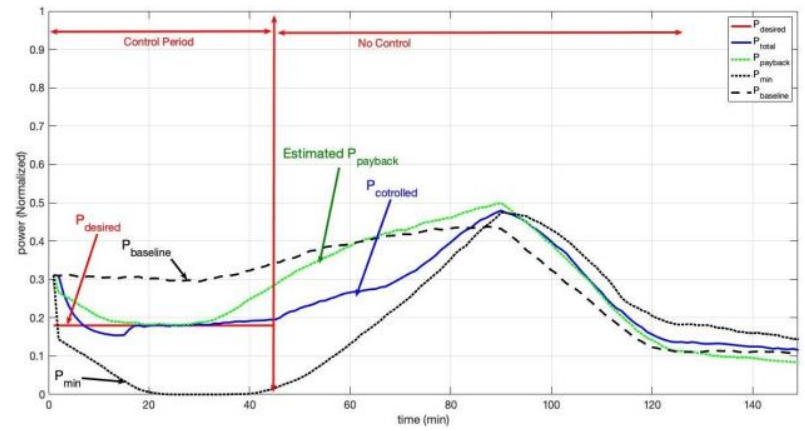

Fig. 7: Predicting how the load will behave once the controller stops after 45 minutes of controlling the load

\section{Conclusions}

Direct load control is a promising method to mitigate fast fluctuations of the generation side, and thermostatically controlled appliances have great potential as a controllable load. However, in order to efficiently control the load, a system operator requires to know the capacity of the load that could be added to or removed from the baseline with an estimation on how long the system could follow a dispatch instruction.

This paper presented a methodology to create a mathematical model for the aggregated power consumption of a population of air conditioners to predict its future load and how much that can be added to or removed from it without disturbing the customers. This information can be used as a basis to develop attainable dispatch instructions by the system operators to a load aggregators to reshape the demand-side power profiles. This model can help to predict: 1) how long a dispatch command can be executed successfully without disturbing the customers, 2) how the load will change once the control interval is over. Simulation results show that the control capacity obtained by the Mathematical model are reliable estimation and can provide a good insight about the controllability of the load.

\section{REFERENCES}

[1] M. Fan, K. Sun, D. Lane, W. Gu, Z. Li, and F. Zhang, "A novel generation rescheduling algorithm to improve power system reliability with high renewable energy penetration," IEEE Transactions on Power Systems, vol. PP, no. 99, pp. 1-1, 2018.

[2] A. Halder, X. Geng, P. R. Kumar, and L. Xie, "Architecture and algorithms for privacy preserving thermal inertial load management by a load serving entity," in 2017 IEEE Power Energy Society General Meeting, July 2017, pp. 1-1.

[3] Y. Cheng, "Methods for mitigating the effects of intermittent energy production of photovoltaic sources," in 2011 International Conference on Power Engineering, Energy and Electrical Drives, May 2011, pp. 16.

[4] L. Hucheng, W. Xinwei, Y. Yubo, S. Wei, and G. Yanfeng, "Simulation and analysis of electric water heater load regulation model based on direct load control," in 2017 IEEE Conference on Energy Internet and Energy System Integration (EI2), Nov 2017, pp. 1-5.

[5] M. Shaad, C. P. Diduch, M. E. Kaye, and L. Chang, "A basic load following control strategy in a direct load control program," in 2015 IEEE Electrical Power and Energy Conference (EPEC), Oct 2015, pp. 339-343.

[6] T. Mega, S. Kitagami, S. Kawawaki, and N. Kushiro, "Experimental evaluation of a fast demand response system for small/medium-scale office buildings," in 2017 31st International Conference on Advanced Information Networking and Applications Workshops (WAINA), March 2017, pp. 291-295. 
[7] M. Shad, A. Momeni, R. Errouissi, C. P.Diduch, M. E. Kaye, and L. Chang, "Identification and estimation for electric water heaters in direct load control programs," IEEE Transactions on Smart Grid, vol. 8, no. 2, pp. 947-955, March 2017.

[8] B. Vatani, B. Chowdhury, and J. Lin, "The role of demand response as an alternative transmission expansion solution in a capacity market," IEEE Transactions on Industry Applications, vol. 54, no. 2, pp. 10391046, March 2018

[9] Q. Shi, F. Li, G. Liu, D. Shi, Z. Yi, and Z. Wang, "Thermostatic load control for system frequency regulation considering daily demand profile and progressive recovery," IEEE Transactions on Smart Grid, vol. 10, no. 6, pp. 6259-6270, Nov 2019.

[10] Y. Wang, Y. Tang, Y. Xu, and Y. Xu, "A distributed control scheme of thermostatically controlled loads for the building-microgrid community," IEEE Transactions on Sustainable Energy, vol. 11, no. 1, pp. 350-360, Jan 2020.

[11] S. Kundu, N. Sinitsyn, S. Backhaus, and I. Hiskens, Modeling and control of thermostatically controlled loads. Power Systems Computation Conference, 2011.

[12] W. Zhang, J. Lian, C. Y. Chang, and K. Kalsi, "Aggregated modeling and control of air conditioning loads for demand response," IEEE Transactions on Power Systems, vol. 28, no. 4, pp. 4655-4664, Nov 2013.

[13] N. Chakraborty, A. Mondal, and S. Mondal, "Intelligent scheduling of thermostatic devices for efficient energy management in smart grid," IEEE Transactions on Industrial Informatics, vol. 13, no. 6, pp. 28992910, Dec 2017.

[14] H. Mortaji, S. H. Ow, M. Moghavvemi, and H. A. F. Almurib, "Load shedding and smart-direct load control using internet of things in smart grid demand response management," IEEE Transactions on Industry Applications, vol. 53, no. 6, pp. 5155-5163, Nov 2017.

[15] S. Chen, Q. Chen, and Y. Xu, "Strategic bidding and compensation mechanism for a load aggregator with direct thermostat control capabilities," IEEE Transactions on Smart Grid, vol. 9, no. 3, pp. 2327-2336, May 2018.

[16] J. Mathieu, S. Koch, and D. Callaway, "State estimation and control of electric loads to manage real-time energy imbalance," IEEE Transactions on Power Systems, vol. 28, no. 1, pp. 430-440, 12013.

[17] N. Mahdavi, J. H. Braslavsky, M. M. Seron, and S. R. West, "Model predictive control of distributed air-conditioning loads to compensate fluctuations in solar power," IEEE Transactions on Smart Grid, vol. 8 , no. 6, pp. 3055-3065, Nov 2017.

[18] S. H. Tindemans, V. Trovato, and G. Strbac, "Decentralized control of thermostatic loads for flexible demand response," IEEE Transactions on Control Systems Technology, vol. 23, no. 5, pp. 1685-1700, Sept 2015.

[19] K. Meng, D. Wang, Z. Y. Dong, X. Gao, Y. Zheng, and K. P. Wong, "Distributed control of thermostatically controlled loads in distribution network with high penetration of solar pv," CSEE Journal of Power and Energy Systems, vol. 3, no. 1, pp. 53-62, March 2017.

[20] C.-R. Chen, S.-C. Shih, and S.-C. Hu, "Short-term electricity forecasting of air-conditioners of hospital using artificial neural networks," in 2005 IEEE/PES Transmission Distribution Conference Exposition: Asia and Pacific, Aug 2005, pp. 1-5.

[21] D.-X. Niu, Q. Wanq, and J.-C. Li, "Short term load forecasting model using support vector machine based on artificial neural network," in 2005 International Conference on Machine Learning and Cybernetics, vol. 7, Aug 2005, pp. 4260-4265 Vol. 7

[22] S. Singh, S. Hussain, and M. A. Bazaz, "Short term load forecasting using artificial neural network," in 2017 Fourth International Conference on Image Information Processing (ICIIP), Dec 2017, pp. 1-5.

[23] C. Perfumo, J. H. Braslavsky, and J. K. Ward, "Model-based estimation of energy savings in load control events for thermostatically controlled loads," IEEE Transactions on Smart Grid, vol. 5, no. 3, pp. 1410-1420, May 2014.

[24] R. Gao, , and X. Liu, "Short-term load forecasting based on least square support vector machine combined with fuzzy control," in Proceedings of the 10th World Congress on Intelligent Control and Automation, July 2012, pp. 1048-1051.

[25] N. Lu and Y. Zhang, "Design considerations of a centralized load controller using thermostatically controlled appliances for continuous regulation reserves," IEEE Transactions on Smart Grid, vol. 4, no. 2, pp. 914-921, June 2013

[26] S. E. Z. Soudjani and A. Abate, "Aggregation and control of populations of thermostatically controlled loads by formal abstractions," IEEE Transactions on Control Systems Technology, vol. 23, no. 3, pp. 975990, May 2015.

[27] M. Liu and Y. Shi, "Model predictive control of aggregated heterogeneous second-order thermostatically controlled loads for ancillary services," IEEE Transactions on Power Systems, vol. 31, no. 3, pp. 1963-1971, May 2016.

[28] N. Mahdavi, J. H. Braslavsky, and C. Perfumo, "Mapping the effect of ambient temperature on the power demand of populations of air conditioners," IEEE Transactions on Smart Grid, vol. PP, no. 99, pp. 1$1,2016$.

[29] C. Perfumo, E. Kofman, J. Braslavsky, and J. Ward, "Load Management: Model-Based Control of Aggregate Power for Populations of Thermostatically Controlled Loads," Energy Conversion and Management, vol. 55, pp. 36-48, 2012. [Online]. Available: files/airs.pdf

[30] J. Hu, J. Cao, T. Yong, J. M. Guerrero, M. Z. Q. Chen, and Y. Li, "Demand response load following of source and load systems," IEEE Transactions on Control Systems Technology, vol. 25, no. 5, pp. 15861598, Sept 2017.

[31] S. Bashash and H. K. Fathy, "Modeling and control insights into demand-side energy management through setpoint control of thermostatic loads," in Proceedings of the 2011 American Control Conference, June 2011, pp. 4546-4553.

[32] P. Yazdkhasti and C. P. Diduch, "A mathematical model for the aggregated power consumptions of air conditioners," in 2018 the 6th international conference on smart energy grid engineering, August 2018, pp. $1-8$.

[33] - "A pid controller for direct load control of thermostatically controlled appliances," in 2019 the 58th international conference on Decision and Control, Dec 2019, pp. 1 - 8

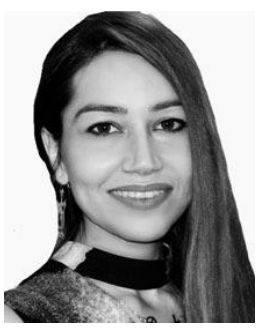

Pegah Yazdkhasti received her B.Sc. \& M.Sc. degree both in Electrical Engineering. She is currently a $\mathrm{PhD}$ Candidate and Research Assistant at the Smart Grid Research Center, Department of Electrical \& Computer Engineering, University of New Brunswick, Canada. She was a Visiting Research Associate at the Queen's University of Belfast, UK. in 2019. Her main research interests include modeling, design, control, signal processing, and application of Machine Learning and AI in Smart Grid and demand-side management.

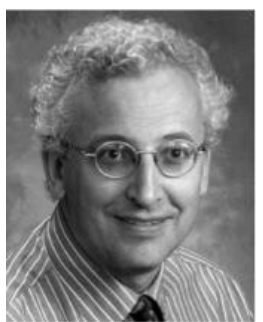

Chris Diduch received the Ph.D. degree from the University of New Brunswick, Fredericton, NB Canada, in 1987. He is currently the Dean of Engineering, and a Professor of Electrical and Computer Engineering at the University of New Brunswick. His research interests include feedback systems, computer control and embedded systems, system identification, and failure detection and isolation. $\mathrm{He}$ is a registered Professional Engineer of APEGNB.

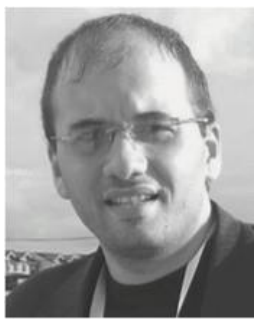

Ahmad Elkhateb (M'10-SM'17) received the B.Eng. and M.Sc. degrees from the Islamic University of Gaza, Palestine, in 2005 and 2007, respectively, the $\mathrm{PhD}$ degree in electrical engineering from the University of Malaya, Kuala Lumpur, Malaysia, in 2013, and the PGCHET from Queen's University, Belfast, UK, in 2019.

$\mathrm{He}$ is a Lecturer in power electronics with the School of Electronics, Electrical Engineering and Computer Science, Queen's University, Belfast, UK. His main research interests include power electronics, digital control, $\mathrm{dc} / \mathrm{dc}$ converters, photovoltaic power generation, and grid integration. Dr Elkhateb is a Fellow of the Higher Education Academy (FHEA), Member of the EPSRC Associate Review College and Associate Editor for the IEEE Access, and the IET Power Electronics. 